\title{
Odnos učiteljev do empirično podprtega poučevanja: primerjalna analiza stališč med prihodnjimi učitelji in učitelji eksperti v zgodnjem osnovnošolskem izobraževanju
}

\author{
Urška Žerak ${ }^{*}$ in Mojca Juriševič \\ Oddelek za temeljni pedagoški študij, Pedagoška fakulteta, Univerza v Ljubljani
}

\begin{abstract}
Povzetek: Poučevanje, ki temelji na empiričnih dokazih in ne le intuitivnih praksah, učiteljem omogoča, da svoje učne metode in poučevalne pristope kakovostno načrtujejo, izvajajo in nadalje razvijajo ter tako učencem nudijo učinkovito podporo pri učenju $\mathrm{v}$ specifičnih učnih kontekstih. Pretekle raziskave kažejo, da imajo stališča učiteljev na splošno pomemben vpliv na njihovo pedagoško delo, vendar je področje specifičnega odnosa učiteljev do empirično podprtega poučevanja še skromno raziskano. Namen te raziskave je zato ugotoviti, kakšna so stališča prihodnjih učiteljev in učiteljev ekspertov do raziskovanja in uporabe raziskovalnih izsledkov v poučevalni praksi. V raziskavi so sodelovali študenti drugega letnika univerzitetnega študijskega programa Razredni pouk na Pedagoški fakulteti Univerze v Ljubljani $(n=181)$ in njihovi mentorji, učitelji praktiki $(n=181)$. V okviru mešanega raziskovalnega načrta so udeleženci izpolnili samoocenjevalni vprašalnik o odnosu do raziskovanja na področju izobraževanja. Poleg tega so odgovorili tudi na dve vprašanji, ki sta bili povezani z izvedbo študentskega raziskovalnega projekta na šolah. Rezultati so pokazali, da imajo prihodnji učitelji in učitelji eksperti podobno visoka pozitivna stališča na področju zaznanih potreb in pomembnosti raziskovanja, na področju zaznane uporabnosti raziskovalnih spoznanj za poučevanje pa imajo prihodnji učitelji statistično značilno bolj pozitivna stališča kot učitelji eksperti $(d=0,52)$.
\end{abstract}

Ključne besede: empirično podprto poučevanje, učitelji, stališča do raziskovanja, izobraževanje učiteljev

\section{Teachers' attitudes towards evidence-based teaching: A comparative analysis between prospective teachers and expert teachers in primary education}

\author{
Urška Žerak ${ }^{*}$ and Mojca Juriševič \\ Department of Education Studies, Faculty of Education, University of Ljubljana, Slovenia
}

\begin{abstract}
Evidence-based teaching, which outgrows intuitive practices, enables teachers to plan, perform and further develop their teaching methods and approaches in order to provide students with effective learning support in specific learning contexts. Past research has shown that teachers' attitudes generally have a significant impact on their teaching practices. However, research in the specific field of teachers' attitudes towards evidence-based teaching is still scarce. The purpose of this research is therefore to determine the teachers' attitudes towards empirically supported teaching and use of research findings in teaching practice, as well as to examine potential differences in their attitudes regarding the level of professional expertise (prospective teachers vs. expert teachers). The sample included second-year undergraduate pre-service primary teachers $(n=181)$ and their mentors, in-service primary teachers $(n=181)$. Within the mix-method research design, participants filled out a self-assessment questionnaire about teachers' attitudes towards educational research. In addition, they answered to two questions related to the implementation of a student research project at schools. Results revealed that prospective teachers and expert teachers have similarly high positive attitudes on two dimensions: perceived necessity and value of educational research. In the dimension of perceived applicability of research findings, prospective teachers have statistically significantly more positive attitudes than expert teachers do $(d=0.52)$.
\end{abstract}

Keywords: evidence-based teaching, teachers, attitudes towards educational research, teacher education

\footnotetext{
*Naslov/Address: Urška Žerak, Oddelek za temeljni pedagoški študij, Pedagoška fakulteta, Univerza v Ljubljani, Kardeljeva ploščad 16, 1000 Ljubljana, e-mail: urska.zerak@pef.uni-lj.si
}

Članek je licenciran pod pogoji Creative Commons Attribution 4.0 International licence. (CC-BY licenca). The article is licensed under a Creative Commons Attribution 4.0 International License (CC-BY license). 
Stališča lahko opredelimo kot relativno trajne kognitivne oz. osebnostne strukture, ki predstavljajo predispozicije za odzivanje posameznika na določen način. Vplivajo na to, kako posameznik zaznava in doživlja določene situacije in objekte ter usmerjajo njegovo pozornost. Predstavljajo integracijo treh vidikov osnovnih duševnih funkcij: (a) kognitivne komponente, ki se nanaša na informacije in znanje posameznika o določenem objektu, osebi ali situaciji; (b) čustvene komponente, ki obsega pozitivna oz. negativna občutja ter ocenjevanje objektov stališč in (c) motivacijske komponente, ki zajema posameznikove vedenjske namere ali dejansko vedenje do določenega objekta, osebe ali situacije (Ajzen in Fishbein, 1977; Ule, 2009). Tako kot vrednote imajo tudi stališča pomemben vpliv na posameznikova prepričanja in vedenje. Razvijajo se postopoma na podlagi preteklih in sedanjih izkušenj ter se lahko spreminjajo zaradi družbenih vplivov oz. motivacije posameznika (Albarracin, Johnson, Zana in Kumkale, 2005). Pomagajo nam poenostaviti razumevanje posameznih konstruktov in zagotavljajo smernice za vedenje (približevanje oz. izogibanje) v določenih situacijah in do določenih objektov ali posameznikov (Maio in Haddock, 2007). Poleg tega imajo stališča ključno vlogo pri opredelitvi vedenja ter organizaciji znanja in informacij (Pajares, 1992; Maio in Haddock, 2007).

Razdevšek-Pučko (1990) je izpostavila pomen stališč na področju izobraževanja učiteljev, in sicer je vzgojnoizobraževalna stališča opredelila kot »skupino socialnih stališč, ki se oblikujejo z osebnimi izkušnjami, s posredovanimi izkušnjami in z odnosi drugih ter s strokovnim znanjem. Imajo spoznavno, čustveno in akcijsko funkcijo, predstavljajo pripravljenost posameznika za različno ravnanje $v$ posameznih vzgojno-izobraževalnih situacijah, kar pomeni, da posredno in/ali neposredno usmerjajo učiteljeve odnose in ravnanje v konkretnih učno-vzgojnih situacijah.« (str. 6)

Stališča učiteljev o izobraževanju vključujejo prepričanja o zmožnosti vplivanja na uspešnost učencev, o naravi znanja (epistemološka prepričanja), o dejavnikih učiteljevega ali učenčevega delovanja (atribucije, lokus nadzora, motivacija, testna anksioznost), o zaznavi sebe in samovrednotenju (samopodoba, samospoštovanje) ter zaznani samoučinkovitosti (Pajares, 1992). Oblikujejo se že zgodaj v strokovnem razvoju, nato pa ostajajo relativno stabilna. Služijo kot filter, preko katerega si učitelji razlagajo nove informacije. Pajares (1992) njihovo naravo pojasnjuje v treh razsežnostih: čustvena (stališča vzbujajo pri posamezniku določena čustva, kar olajša njihovo shranjevanje $\mathrm{v}$ dolgoročnem spominu), ocenjevalna (stališča določajo, kaj je dobro oz. vredno in kaj ni) in epizodična (stališča so tesno povezana s specifičnimi situacijami oz. izkušnjami).

Raziskave kažejo, da imajo stališča učiteljev pomemben vpliv na njihovo pedagoško delo v razredu (Ekiz, 2006; Everton, Galton in Pell, 2002). Zato je pomembno, da prihodnji učitelji razvijejo pozitivna stališča do raziskav na področju izobraževanja že med študijem, saj bodo tako raziskovalne izsledke prebirali, jih kritično vrednotili ter uporabljali njihove izsledke pri pedagoškem delu (Joram, 2007). Prihodnji učitelji bi se morali že med študijem seznaniti z znanstvenimi raziskavami in se preizkusiti v izvedbi manjših raziskovalnih projektov, da bi razumeli pomen raziskovanja in oblikovali pozitiven odnos do empirično podprtega poučevanja (Tosun,
2014). Stališča prihodnjih učiteljev do izobraževanja namreč igrajo ključno vlogo pri pridobivanju in interpretaciji znanja in vedenja o učiteljevem poučevanju (Pajares, 1992).

Za razvoj pedagoškega dela učiteljev je odločilnega pomena, da je podprto z empiričnimi izsledki, ki zagotavljajo ustrezno strokovno raven kakovosti poučevanja (Brown in Zhang, 2017; Hargreaves, 1996; Hiebert, Gallimore in Stigler, 2002). Raziskovalno delo učitelju omogoča širše polje strokovnih premislekov in sprejemanja odločitev, narekuje vsebine interakcij z učenci, analizo specifičnih pedagoških situacij ter sprotno preverjanje učinkovitosti uporabljenih učnih metod oziroma pedagoških pristopov (Lamanauskas in Augiene, 2017). Poučevanje, ki temelji na empiričnih dokazih in ne le intuitivnih praksah, učitelju namreč omogoča, da svoje učne metode in pristope izboljša ter učencem nudi učinkovito podporo pri učenju v specifičnih učnih kontekstih (CochranSmith, 2005). Koristno povezavo med teorijo in prakso predstavlja polje, v okviru katerega učitelji sami raziskujejo različne vidike poučevanja in učenja, saj tako lahko bolje razumejo svoje poučevalne prakse in jih tudi preoblikujejo na osnovi spremljanja in evalvacije (Admiraal, Buijs, Claessens, Honing in Karkdijk, 2017).

Stališča učiteljev do raziskovanja oz. raziskovalnih spoznanj v kontekstu poučevanja naj bi se oblikovala že v času študija. Ugotovitve raziskave, ki so jo izvedli İlhan, Yilmaz in Dede (2015) in v kateri je sodelovalo 517 študentov pedagoških fakultet $\mathrm{v}$ Turčiji kažejo, da imajo študenti v splošnem pozitivna stališča do raziskav na področju izobraževanja, pri čemer ženske izkazujejo bolj pozitivna stališča v primerjavi z moškimi, kar je še posebej razvidno na dimenziji uporabnost raziskav (odnos do uporabne vrednosti ugotovitev raziskav na področju izobraževanja $\mathrm{v}$ pedagoški praksi). $\mathrm{V}$ raziskavi je bila uporabljena lestvica Teachers Attitude Scale Towards Educational Research (TASTER; İlhan, Şekerci, Sözbilir in Yıldırım, 2013), ki jo sestavljajo trije faktorji, in sicer: (a) potreba po raziskovanju vključuje postavke, ki se nanašajo na zaznano pomembnost izvedbe raziskav na področju izobraževanja za razvoj pedagoških praks; (b) vrednost raziskav vključuje postavke, ki izpostavljajo vlogo raziskav na področju izobraževanja pri strokovnem razvoju učiteljskega poklica; (c) uporabnost raziskav vključuje postavke, ki opisujejo uporabno vrednost ugotovitev raziskav na področju izobraževanja v pedagoški praksi. Tosun (2014) navaja, da so prihodnji učitelji, ki so obiskovali predmet metode znanstvenega raziskovanja, po zaključku predmeta poročali o nižji anksioznosti do izvedbe empiričnih raziskav ter izboljšani samoučinkovitosti na področju raziskovanja. Byman in sodelavci (2009) so izvedli raziskavo, v katero sta bili vključeni dve skupini študentov, pri čemer so imeli študenti v prvi skupini že nekaj izkušenj s poučevanjem, medtem ko študenti v drugi skupini niso imeli nobenih izkušenj s poučevanjem. Rezultati so pokazali, da sta obe skupini izkazovali pozitivna stališča do uporabe raziskovalnih spoznanj v kontekstu poučevanja, pri tem pa so študenti, ki so imeli že nekaj let izkušenj s poučevanjem, izkazovali bolj pozitivna stališča do empirično podprtega poučevanja, kar avtorji pripisujejo konkretnim izkušnjam pri poučevanju. Izsledki raziskave Evertona, Galtona in Pella (2002) kažejo na pozitiven odnos učiteljev do empirično podprtega poučevanja. Učitelji so na splošno 
pozitivno vrednotili raziskave na področju izobraževanja, ki se osredotočajo na specifične učne dejavnosti, učne pristope ali z dokazi podprte metode učinkovitega učenja. Kljub temu so učitelji poročali, da se ne počutijo zadosti usposobljene za oblikovanje in izvajanje raziskovalnega dela, ki bi jim koristilo pri izboljšanju lastnih poučevalnih praks.

$\mathrm{Na}$ drugi strani pa ugotovitve nekaterih raziskav (Gitlin, Barlow, Burbank, Kauchak in Stevens, 1999; Shaw, Holbrook, Scevak in Bourke, 2008; Pendry in Husbands, 2000) kažejo, da imajo študenti na področju izobraževanja negativen oz. apatičen odnos do raziskovanja ter njegove potencialne uporabnosti. V raziskavi Gitlina in sodelavcev (1999), v kateri so študentje izvajali raziskovalne projekte kot del obveznosti pri predmetu, so raziskovalci ugotovili, da so stališča prihodnjih učiteljev o naravi in uporabnosti raziskovanja $\mathrm{v}$ kontekstu poučevanja ostala nespremenjena in se niso izboljšala, kljub temu da so udeleženci imeli konkretno izkušnjo $\mathrm{z}$ izvedbo raziskovalnega projekta. Lamanauskas in Augiene (2017) poročata o nizki motivaciji dodiplomskih in podiplomskih študentov ter prihodnjih učiteljev naravoslovja za vključevanje v raziskovalno delo. Med dejavniki, ki pomembno prispevajo k dvigu motiviranosti študentov za raziskovanje, sta se v njuni študiji kot najbolj pomembna izkazala primerno študijsko okolje ter podpora tutorjev. Hennessy in Lynch (2019) ugotavljata, da prihodnji učitelji ustrezno razumejo vlogo raziskovanja na področju izobraževanja pri njihovem strokovnem razvoju, vendar hkrati izkazujejo nizko pripravljenost za vključevanje v raziskovalne aktivnosti. Izsledek se zdi razumljiv, saj svojo primarno funkcijo učitelji razumejo predvsem kot poučevanje in ne raziskovanje, ob tem pa se zavedajo pomembnosti upoštevanja strokovnih podlag za kakovostno poučevanje, kar je vsekakor želen cilj na področju izobraževanja učiteljev. Gore in Gitlin (2004) sta raziskala odnos prihodnjih učiteljev in učiteljev v praksi do raziskovanja na področju izobraževanja. Ugotovila sta, da slednji ne zaznavajo vrednosti oz. koristnosti raziskav na področju izobraževanja. Obe skupini učiteljev sta izrazili pomisleke glede praktičnosti, konteksta, verodostojnosti in dostopnosti raziskav na področju izobraževanja. O podobnih rezultatih poroča Ahuja (2012), ki je ugotovila, da učitelji ne uporabljajo raziskovalnih ugotovitev, ker niso seznanjeni $\mathrm{z}$ raziskavami, ki se izvajajo na področju raziskovanja. Učitelji so poročali, da imajo težave $\mathrm{z}$ razumevanjem uporabljene terminologije $\mathrm{v}$ raziskavah ter $\mathrm{z}$ dostopom do raziskovalnih izsledkov. Po drugi strani sodelujoči učitelji uporabljajo predvsem intuitivne pristope, ki izhajajo iz dobrih praks oz. pedagoških izkušenj njih samih ali drugih učiteljev.

$\mathrm{Na}$ osnovi dostopne literature se zdi, da lahko razlike v raziskovalnih izsledkih o odnosu učiteljev ekspertov in prihodnjih učiteljev do empirično podprtega poučevanja delno pripišemo naslednjim dejavnikom: metodološkemu pristopu (kvantitativni vs. kvalitativni), specifičnemu področju študija oz. področju poučevanja (geografija, matematika, naravoslovje, razredni pouk, zgodovina) ter specifičnim izobraževalnim kontekstom posameznih držav (Avstralija, Finska, Indija, Litva, Nizozemska, Turčija, Združene države Amerike, Združeno Kraljestvo Velike Britanije in Severne Irske). Zagotovo bi bilo to domnevo smiselno sistematično raziskati v prihodnje.
Stališča učiteljev do empirično podprtega poučevanja so pomembna za oblikovalce edukacijskih politik ter raziskovalce na področju izobraževanja, saj so učitelji ključni izvajalci izobraževalnega procesa (Beycioglu, Ozer in Ugurlu, 2010). Za razvoj kakovostnih izobraževalnih praks je pomembno, da so učitelji odprti za spremembe, da stalno spoznavajo, spremljajo in evalvirajo svoje pedagoško delo ter na osnovi proučevanja lastne prakse razvijajo in izboljšujejo svoje poučevalne pristope (Krek in Vogrinc, 2008). Evropski dokumenti o temeljnih kompetencah učiteljev dajejo posebni poudarek spodbujanju empirično podprtega poučevanja in opisujejo učitelja kot refleksivnega praktika, ki je aktivno vključen $v$ proces izvajanja raziskav in kritično vključuje znanstvena spoznanja $\mathrm{v}$ svoje poučevalne prakse (Caena, 2011; Krek in Vogrinc, 2008).

Borg (2003) je opredelil naslednje dejavnike, ki vplivajo na oblikovanje stališč učiteljev: izobraževanje (pretekle učne izkušnje učiteljev v vlogi učencev), strokovno delo (programi profesionalnega usposabljanja učiteljev), kontekstualni dejavniki (vplivajo na spremembo stališč, ko se pojavi neskladje med stališči ter praktičnimi izkušnjami učitelja) ter učiteljevo pedagoško delo (nezavedno in/ali preko zavestne učiteljeve refleksije vpliva na spremembo stališč). Pri oblikovanju stališč učiteljev ima pomembno vlogo dodiplomsko izobraževanje, ki mora temeljiti na sodobnih raziskovalnih spoznanjih in kritično reflektirati ugotovitve posameznih raziskav o stališčih učiteljev ter jih smiselno upoštevati pri oblikovanju programov izobraževanja učiteljev (Borg, 2003; Krek in Vogrinc, 2008).

$\mathrm{Na}$ tem mestu je mogoče skleniti, da je pomen stališč v sodobnem času možno razumeti v smislu predpostavke, da mora kakovostno poučevanje temeljiti na empiričnih dokazih oz. izhajati iz strokovnih načel, ki imajo empirične podlage (Brown in Zhang, 2017; Leat, Reid in Lofthouse, 2015). Kljub temu pa je v izobraževalnem kontekstu le malo znanega o stališčih učiteljev do uporabe raziskovalnih izsledkov (Cain, 2015; Craig, 2009; Taylor, 2013). Zato pričakujemo, da bomo z izsledki te raziskave pridobili natančnejši vpogled v ozadje proučevanega pojava, predvsem v smislu dopolnitve obstoječih neskladij o odnosu učiteljev do empirično podprtega poučevanja, še posebej v slovenskem vzgojnoizobraževalnem kontekstu, kjer to področje še ni bilo raziskano. Natančneje, z raziskavo smo nameravali ugotoviti dvoje: (1) kakšna so stališča prihodnjih učiteljev in učiteljev ekspertov do raziskovanja in uporabe raziskovalnih izsledkov pri poučevanju in (2) v skladu z že omenjenimi empiričnimi spoznanji o vplivu izobraževalnega procesa na oblikovanje stališč učiteljev nas je zanimalo, kako v raziskavo vključeni skupini učiteljev ${ }^{1}$ ocenjujeta koristnost raziskovalnega procesa in rezultatov konkretno izvedenih študentskih projektov $\mathrm{v}$ okviru študijskega procesa.

\footnotetext{
${ }^{1}$ Poimenovanje skupin prihodnjih učiteljev in učiteljev ekspertov je bilo za namen raziskave prevzeto po Berlinerju (2001), pri čemer so prihodnji učitelji pojmovani kot študentje, ki se izobražujejo za učiteljski poklic, učitelji eksperti pa so kompetentni učitelji praktiki, ki so v primeru te raziskave tudi mentorji študentom.
} 
Tabela 1. Indeksi prileganja za eno- in trifaktorski model Lestvice za merjenje stališč učiteljev do raziskovanja $v$ izobraževanju $(N=362)$

\begin{tabular}{lccccccc}
\hline Model & $\chi^{2}$ & $d f$ & CFI & TLI & RMSEA & IZ (90 \%) za RMSEA & SRMR \\
\hline Enofaktorski model & $843,63^{*}$ & 190 & 0,90 & 0,89 & 0,09 & $0,086-0,100$ & 0,08 \\
Trifaktorski model & $442,77^{*}$ & 167 & 0,99 & 0,99 & 0,07 & $0,060-0,075$ & 0,06 \\
\hline
\end{tabular}

Opombe. $d f=$ prostostne stopnje, CFI = Comparative Fit Index, TLI = Tucker-Lewis Index, RMSEA = Root Mean Square Error of Approximation, $\mathrm{IZ}=$ interval zaupanja, $\mathrm{SRMR}=$ Standardized Root Mean Square Residual ${ }^{*} p<0,001$.

\section{Metoda}

\section{Udeleženci}

V priložnostni vzorec so bili vključeni prihodnji učitelji, študenti drugega letnika prvostopenjskega študijskega programa Razredni pouk Pedagoške fakultete Univerze $\mathrm{v}$ Ljubljani $(n=181)$, ki so obiskovali seminar pri predmetu Pedagoška psihologija, ter učitelji eksperti, profesorji razrednega pouka $\mathrm{z}$ različnih osnovnih šol v Sloveniji, ki so bili mentorji študentom na pedagoški praksi $(n=181)$. Večina sodelujočih študentov je bila ženskega spola (94\%), prav tako je bila ženskega spola večina sodelujočih mentorjev (98\%). Povprečna starost prihodnjih učiteljev je bila 21 let $(S D=0,48)$, povprečna starost učiteljev ekspertov je bila 44 let $(S D=7,37)$. Udeležba $\mathrm{v}$ raziskavi je bila prostovoljna. Udeležencem so bili predhodno predstavljeni temeljni vidiki raziskave, zagotovljeno je bilo varstvo osebnih podatkov.

\section{Pripomočki}

Lestvica za merjenje stališč učiteljev do raziskovanja v izobraževanju (Teachers Attitude Scale Towards Educational Research ali TASTER; İlhan, Şekerci, Sözbilir in Yıldırım, 2013).

Za potrebe raziskave je bila $\mathrm{z}$ dovoljenjem avtorjev $\mathrm{v}$ slovenski jezik prevedena Lestvica za ocenjevanje stališč učiteljev do raziskav v izobraževanju po načelu vzvratnega prevoda (Brislin, 1986). Lestvico sestavlja 20 postavk, ki preverjajo stališča učiteljev do raziskovanja na treh dimenzijah: potreba po raziskovanju (primer: »Raziskovalci na področju izobraževanja zagotavljajo uporabne informacije, ki jih lahko učitelj uporabi pri poučevanju.«), vrednost raziskav (primer: " Za kakovostno pedagoško delo učitelja je pomembno, da pri svojem delu uporablja raziskovalne izsledke.«), uporabnost raziskav (primer: »Raziskave, ki jih izvajajo univerzitetni raziskovalci, so namenjene zgolj njihovemu lastnemu kariernemu razvoju.«). Postavke se ocenjuje na 5-stopenjski ocenjevalni lestvici ( 1 - sploh se ne strinjam; 5 - popolnoma se strinjam). Končni rezultat je seštevek ocen na posameznih dimenzijah, pri tem pa so nekatere postavke $(4,5,8,13,15$, $18,19)$ obratno vrednotene. Ilhan, Yilmaz in Dede $(2015)$ poročajo o naslednjih koeficientih zanesljivosti: $\alpha_{\text {celotna }}$ lestvica $=0,87, \alpha_{\text {potreba }}=0,77, \alpha_{\text {vrednost }}=0,79$ in $\alpha_{\text {uporabnost }}=0,71$.

Uporabljen instrument še ni bil ustrezno prirejen za slovensko kulturno in jezikovno okolje. Zaradi tega smo z uporabo konfirmatorne faktorske analize preverili njegovo notranjo strukturo na slovenskih podatkih. Analizo smo izvedli v programu RStudio (2015) z uporabo statističnega paketa lavaan (Rosseel, 2012). Pri tem smo kot cenilko parametrov uporabili WLSMV (robustna različica cenilke obteženih najmanjših kvadratov; angl. Weighted Least Squares Means and Variance Adjusted), ki je v lavaanu privzeta cenilka za ordinalne podatke. Pri odločanju o ustreznosti prileganja modela smo uporabili naslednje mere: $\chi^{2}$, RMSEA (angl. Root Mean Square Error of Approximation), CFI (angl. Comparative Fit Index) in TLI (angl. Tucker Lewis Index). Za določanje ustreznosti prileganja modelov smo uporabili naslednje mejne vrednosti: RMSEA (ali blizu) < 0,08; CFI > (ali blizu) 0,90; TLI $>$ (ali blizu) 0,90. Prileganje 1-faktorskega je bilo pogojno zadovoljivo, prileganje 3 -faktorskega modela pa je bilo ustrezno (tabela 1). Standardizirane faktorske nasičenosti so bile $\mathrm{v}$ povprečju dovolj visoke: potreba po raziskovanju, $M(\lambda)=0,66$; vrednost raziskav, $M(\lambda)=0,71$; uporabnost raziskav $M(\lambda)=0,67$. Koeficienti zanesljivosti za posamezne dimenzije na danem vzorcu so bili ustrezni v razponu od 0,79 do 0,90 (tabela 2).

Vprašalnik o izvedenem študijskem raziskovalnem projektu. Samoocenjevalni vprašalnik je bil zasnovan za namen preverjanja odnosa prihodnjih učiteljev (študentov) in učiteljev ekspertov (mentorjev študentov) do izvedenega raziskovalnega projekta $\mathrm{v}$ okviru pedagoške prakse pri predmetu Pedagoška psihologija na študijskem programu Razredni pouk na Pedagoški fakulteti Univerze v Ljubljani (Juriševič in Žerak, 2016). Vprašalnik sestavljajo trditev o zaznani koristnosti oz. vrednosti izvedenega raziskovalnega projekta, ki jo udeleženci vrednotijo na 5-stopenjski ocenjevalni lestvici ( 1 - sploh se ne strinjam; 5 - popolnoma

Tabela 2. Opisne statistike za dosežke na Lestvici za merjenje stališč učiteljev do raziskovanja v izobraževanju (N = 362)

\begin{tabular}{lccccccc}
\hline & $M$ & $S D$ & Min & Max & As & $S p l$ & $\alpha$ \\
\hline Potreba po raziskovanju & 3,87 & 0,52 & 2,29 & 5,00 & $-0,28$ & 0,23 & 0,80 \\
Vrednost raziskav & 4,11 & 0,51 & 2,33 & 5,00 & $-0,44$ & 0,28 & 0,79 \\
Uporabnost raziskav & 3,76 & 0,58 & 1,86 & 5,00 & 0,18 & $-0,23$ & 0,80 \\
Celotna lestvica & 3,90 & 0,46 & 2,25 & 5,00 & $-0,03$ & 0,79 & 0,90 \\
\hline
\end{tabular}

Opombe. $A s=$ asimetričnost, $S p l=$ sploščenost, $\alpha=$ Cronbachov alfa koeficient zanesljivosti. 
Tabela 3. Razlike v stališčih do raziskovanja med prihodnjimi učitelji in učitelji eksperti

\begin{tabular}{|c|c|c|c|c|c|c|c|}
\hline & \multicolumn{2}{|c|}{$\begin{array}{l}\text { Prihodnji učitelji } \\
\quad(n=181)\end{array}$} & \multicolumn{2}{|c|}{$\begin{array}{l}\text { Učitelji eksperti } \\
\quad(n=181)\end{array}$} & \multirow[b]{2}{*}{$t(361)$} & \multirow[b]{2}{*}{$p$} & \multirow[b]{2}{*}{$d$} \\
\hline & $M$ & $S D$ & $M$ & $S D$ & & & \\
\hline Celotna lestvica & 3,98 & 0,46 & 3,83 & 0,46 & $-3,13$ & $<0,01$ & 0,33 \\
\hline Potreba po raziskovanju & 3,91 & 0,52 & 3,84 & 0,52 & $-1,36$ & 0,18 & 0,13 \\
\hline Vrednost raziskav & 4,14 & 0,52 & 4,07 & 0,49 & $-1,45$ & 0,15 & 0,14 \\
\hline Uporabnost raziskav & 2,39 & 0,56 & 2,10 & 0,56 & $-4,92$ & $<0,01$ & 0,52 \\
\hline
\end{tabular}

se strinjam) ter šest odprtih vprašanj o odnosu do izvedenega raziskovalnega projekta. Za namen te raziskave so bile iz opisanega vprašalnika uporabljene: trditev o zaznani koristnosti oz. vrednosti izvedenega raziskovalnega projekta ter dve odprti vprašanji o zaznanih prednostih (Kaj vas je motiviralo za izvedbo raziskovalnega projekta?) oz. pomanjkljivostih (Kaj vas je oviralo pri izvedbi raziskovalnega projekta?) raziskovalnega projekta.

\section{Postopek}

Z namenom ozaveščanja o pomenu raziskovalne vloge učitelja so študentje drugega letnika študijskega programa Razredni pouk $\mathrm{v}$ okviru seminarskih vaj pri predmetu Pedagoška psihologija na Pedagoški fakulteti Univerze v Ljubljane pridobili potrebna metodološka in vsebinska znanja za pripravo raziskave na šoli. Nato so med pedagoško prakso pod mentorstvom učiteljev praktikov empirično raziskali izbran psihološki pojav. Po zaključku so študenti in njihovi mentorji izpolnili Lestvico za merjenje stališč učiteljev do raziskovanja ter Vprašalnik o izvedenem raziskovalnem projektu.

Podatki so bili zbrani na Pedagoški fakulteti Univerze v Ljubljani v poletnem semestru študijskih let 2016/17 in 2017/18 in obdelani s statističnim programom IBM SPSS Statistics 20 (IBM Corporation, 2016) in programom RStudio (2015). Pred izvedbo analiz je bila preverjena porazdeljenost spremenljivk; ker ta ni pomembno odstopala od normalne, so bili za nadaljnje analize uporabljeni parametrični testi $(t$ test za neodvisne vzorce), pri tem pa je bil zaradi večkratnih primerjav uporabljen Bonferronijev popravek. Kot mero velikosti učinka je bil izračunan Cohenov $d$. Kvalitativni odgovori so bili analizirani $\mathrm{z}$ uporabo primerjalne analize vsebine $\mathrm{z}$ uporabo odprtega kodiranja izbranih kategorij (Vogrinc, 2008).

\section{Rezultati}

Izsledki o stališčih do empirično podprtega poučevanja, ki so bila predmet te raziskave, so v nadaljevanju predstavljeni $\mathrm{v}$ dveh vsebinskih sklopih. V prvem sklopu so predstavljene ugotovljene razlike med stališči prihodnjih učiteljev in učiteljev ekspertov, $v$ drugem sklopu pa kvalitativne ugotovitve o oceni koristnosti izvedenih raziskovalnih projektov za razumevanje vloge raziskovanja za kakovostno poučevanje.

\section{Stališča prihodnih učiteljev in učiteljev ekspertov do raziskovanja}

$\mathrm{Na}$ podlagi odgovorov udeležencev na postavke na Lestvici za merjenje stališč do raziskav v izobraževanju (TASTER) smo izračunali osnovne opisne statistike. Iz tabele 2 je razvidno, da imajo $\mathrm{v}$ raziskavi udeleženi učitelji $\mathrm{v}$ povprečju pozitivna stališča do raziskovanja na področju izobraževanja; med njimi so najvišje ocenjena stališča na dimenziji vrednost raziskav, sledijo stališča na dimenziji potreba po raziskovanju, najnižje med njimi pa so ocenjena stališča na dimenziji uporabnost raziskav.

$\mathrm{Z}$ namenom preverjanja morebitnih razlik $\mathrm{v}$ stališčih do raziskovanja na področju izobraževanja med obema skupinama učiteljev je bila izračunana serija $t$-testov za neodvisne vzorce. Rezultati, prikazani v tabeli 3 kažejo, da se skupini prihodnjih učiteljev in učiteljev ekspertov statistično značilno razlikujeta $\mathrm{v}$ stališčih na celotni lestvici TASTER ter na dimenziji uporabnost raziskav. Izračunana je bila tudi mera velikosti učinka (Cohenov $d$ ), ki je pokazala, da je velikost učinka razlik v stališčih med skupinama na celotni lestvici nizka, na lestvici uporabnost raziskav pa srednja. $\mathrm{Na}$ lestvicah potreba po raziskovanju in vrednost raziskav se je velikost učinka izkazala kot zanemarljiva.

\section{Zaznana koristnost izvedenega raziskovalnega projekta $z$ vidika prihodnjih učiteljev in učiteljev ekspertov}

Pri obravnavi problema stališč učiteljev do raziskovanja nas je zanimalo, kako prihodnji učitelji in učitelji eksperti zaznavajo koristnost izvajanja raziskovanja $\mathrm{v}$ avtentičnem šolskem kontekstu. Na splošno so učitelji izveden raziskovalni projekt ocenili kot koristen za razumevanje psiholoških razsežnosti pedagoškega dela v razredu (prihodnji učitelji: $M=4,20 ; S D=0,60$; učitelji eksperti: $M=4,64 ; S D=0,53$ ). Analiza je pokazala, da učitelji eksperti statistično značilno višje ocenjujejo koristnost izvedenega projekta kot prihodnji učitelji, $t(179)=6,82, p<0,001, d=0,78$. V tabeli 4 so predstavljeniizsledkivsebinskeanalize odgovorov sodelujočih učiteljev na vprašanje o prednostih in pomanjkljivostih izvedenega raziskovalnega projekta.

Kategorije analiziranih odgovorov učiteljev ekspertov (tabela 4) kažejo, da učitelji eksperti pomen raziskovalnega projekta vidijo predvsem $\mathrm{v}$ spoznavanju psiholoških problemov v razredu (primer: »Prednost je v tem, da študenti že v 
Tabela 4. Zaznane prednosti in pomanjkljivosti izvedene raziskovalne aktivnosti $z$ vidika učiteljev ekspertov $(n=107)$ in prihodnjih učiteljev $(n=130)$

\begin{tabular}{|c|c|c|}
\hline Kategorije & $f$ & $\%$ \\
\hline \multicolumn{3}{|l|}{ Prednosti z vidika učiteljev ekspertov } \\
\hline Spoznavanje psiholoških problemov v razredu & 29 & 27,1 \\
\hline Podpora učitelju pri poučevanju & 28 & 26,2 \\
\hline $\begin{array}{l}\text { Povezava teoretičnega znanja s praktičnimi } \\
\text { izkušnjami }\end{array}$ & 17 & 15,9 \\
\hline Razvoj in prenova izobraževanja & 13 & 12,2 \\
\hline Strokovni razvoj (prihodnjega) učitelja & 10 & 9,4 \\
\hline Analiza lastnega pedagoškega ravnanja & 6 & 5,6 \\
\hline Izkustveno učenje & 4 & 3,7 \\
\hline \multicolumn{3}{|l|}{ Pomanjkljivosti z vidika učiteljev ekspertov } \\
\hline Razkorak med teorijo in prakso & 22 & 55,0 \\
\hline $\begin{array}{l}\text { Premajhna obveščenost o rezultatih raziskav } \\
\text { na področju raziskovanja }\end{array}$ & 8 & 20,0 \\
\hline Časovne omejitve & 7 & 17,5 \\
\hline Presplošno zastavljeni raziskovalni problemi & 3 & 7,5 \\
\hline \multicolumn{3}{|l|}{ Prednosti z vidika prihodnjih učiteljev } \\
\hline Pridobivanje uporabnih izkušenj oz. znanj & 72 & 55,4 \\
\hline Koristno za nadaljnji študij oz. pedagoško delo & 28 & 21,5 \\
\hline $\begin{array}{l}\text { Boljša usvojitev (dolgotrajnost) pridobljenega } \\
\text { znanja }\end{array}$ & 15 & 11,5 \\
\hline Povezava teorije in prakse & 7 & 5,4 \\
\hline Drugačen način dela & 6 & 4,6 \\
\hline Sodelovanje pri raziskovanju & 2 & 1,5 \\
\hline \multicolumn{3}{|l|}{ Pomanjkljivosti $z$ vidika prihodnjih učiteljev } \\
\hline Ni koristno za nadaljnje pedagoško delo & 8 & 72,7 \\
\hline $\begin{array}{l}\text { Odvisno od različnih dejavnikov (čas, } \\
\text { motivacija) }\end{array}$ & 3 & 27,3 \\
\hline
\end{tabular}

času študija predvidijo probleme, ki se pojavljajo med učenci in raziskujejo, kako te probleme reševati.«), v podpori učitelju pri poučevanju (primer: »Menim, da raziskovalno delo, če je osnovano na praktičnih primerih $v$ veliki meri izboljša pedagoško delo učitelja.«) ter v povezovanju teoretičnega znanja s praktičnimi izkušnjami (primer: »Študent ob takšni obliki prakse dobi priložnost povezovanja teoretičnega in praktičnega znanja. Raziskovanje mu omogoča natančnejši in vsestranski vpogled v izbrano tematiko.«). Kot zaznane slabosti navajajo prevelik razkorak med teorijo in prakso (primer: "Zahteve vsakdanjega poučevanja so po mojem mnenju precej oddaljene od raziskav.«) in premajhno obveščenost učiteljev praktikov o rezultatih raziskav, ki se izvajajo na področju izobraževanja (primer: »Pomanjkljivost je v tem, da pogosto nismo seznanjeni z rezultati raziskav.«).

Analiza odgovorov prihodnjih učiteljev (tabela 4) nam po drugi strani pokaže, da prihodnji učitelji koristnost vidijo predvsem $\mathrm{v}$ pridobivanju uporabnih izkušenj oz. znanj (primer: "Z raziskavo lahko prideš do konkretnih, lastnih spoznanj, ne le da bereš teorijo o določeni temi.«), poleg tega jih večina raziskovanje zaznava kot koristno za nadaljnji študij oz. prihodnje pedagoško delo (primer: »S tem na nek način že pridobivamo izkušnje, s pomočjo katerih bomo lahko pri delu reševali resnične probleme v razredu.«).

\section{Razprava}

Namen raziskave je bil ugotoviti, kakšna so stališča prihodnjih učiteljev oz. študentov prvostopenjskega študijskega programa Razredni pouk Univerze v Ljubljani Pedagoške fakultete in učiteljev ekspertov oz. izkušenih učiteljev mentorjev študentom $\mathrm{z}$ različnih osnovnih šol po Sloveniji do raziskovanja in uporabe raziskovalnih izsledkov pri pedagoškem delu. Zanimala nas je tudi ocena koristnosti izvedenega raziskovalnega projekta študentov $\mathrm{v}$ okviru njihove pedagoške prakse $\mathrm{z}$ vidika obeh skupin sodelujočih učiteljev.

Raziskovalni rezultati so pokazali, da imajo tako prihodnji učitelji kot učitelji eksperti pozitivna stališča do raziskovanja in razumejo vlogo raziskovanja pri pedagoškem delu učitelja (kakovostno poučevanje). V povprečju so udeleženci v vzorcu stališča na celotni lestvici ocenili nekoliko višje $(M=3,90) \mathrm{v}$ primerjavi z ocenami stališč študentov pedagoških fakultet $\mathrm{v}$ Turčiji $(M=3,72)$ (İlhan idr., 2015), velikost učinka razlik med skupinama je majhna $(d=0,38)$. Avtorji uporabljene lestvice stališč (İlhan idr., 2013) navajajo naslednje intervalne ocene za interpretacijo stališč: vrednosti med 1,00-2,59 nakazujejo na negativna stališča, vrednosti $2,60-3,40$ nakazujejo na nevtralna stališča ter vrednosti med 3,40-5,00 nakazujejo na pozitivna stališča. Glede na priporočila avtorjev lahko sklenemo, da imajo udeleženci te raziskave pozitivna stališča do empirično podprtega poučevanja. Analiza razlik med skupinama sodelujočih učiteljev je pokazala, da prihodnji učitelji v primerjavi z učitelji eksperti izkazujejo statistično značilno bolj pozitivna stališča do raziskovanja. Statistično značilne razlike med skupinama so se pojavile pri dimenziji uporabnost raziskav, pri čemer prihodnji učitelji v primerjavi z učitelji eksperti pripisujejo raziskavam na področju izobraževanja večjo uporabno vrednost v pedagoški praksi. Zdi se, da so študenti zaradi sodobnih študijskih vsebin bolje ozaveščeni glede pomena empiričnih spoznanj v praksi od učiteljev praktikov (Tosun, 2014; Walter in Hen, 2012). Mogoče je tudi, da so učitelji eksperti zaradi konkretnih izkušenj bolj zadržani do uporabe raziskovalnih izsledkov pri delu v razredu (Akcoltekin, Engin in Sevgin, 2017; Gore in Giltin, 2004). Ena izmed postavk, vključenih v lestvico, kjer je bila povprečna vrednost najnižja, se namreč nanaša na to, da učitelji menijo, da izvedba učne ure po predlaganih spoznanjih raziskovalcev vzame preveč časa $(M=2,92)$. Drug možen razlog je morebiti pomanjkanje dostopa do izsledkov raziskav, saj so učitelji praktiki v svojih odgovorih poročali, da so premalo seznanjeni $\mathrm{z}$ raziskavami, ki se izvajajo na področju izobraževanja oz. da te informacije $\mathrm{z}$ zamudo prihajajo do njih, za razliko od študentov, ki so v okviru svojega študija neposredno v stiku z njimi. Podobno je ugotovila tudi Ahuja (2012), ki poroča, da učitelji ne uporabljajo raziskovalnih ugotovitev, ker z njimi niso seznanjeni in imajo težave $\mathrm{z}$ dostopom do raziskovalnih člankov. Razlike bi bilo nenazadnje smiselno pojasniti z dejstvom, da so učitelji eksperti verjetno pogosto preobremenjeni s sodelovanjem $\mathrm{v}$ različnih raziskavah oz. so prenasičeni $z$ najrazličnejšimi raziskavami, pri tem pa imajo težave $\mathrm{z}$ implementacijo raziskovalnih ugotovitev $\mathrm{v}$ prakso (Greenwood in Abbott, 2001). 
Raziskovalne ugotovitve na tem področju še zdaleč niso enoznačne. Po eni strani določeni avtorji (Byman idr., 2009; İlhan idr., 2015) navajajo, da imajo prihodnji učitelji na splošno pozitivna stališča do raziskovanja na področju izobraževanja, kar se je pokazalo tudi v pričujoči raziskavi. Nasprotno pa ugotovitve drugih študij (Gore in Giltin, 2004; Shaw idr., 2008) kažejo, da imajo prihodni učitelji in učitelji v praksi negativen oz. apatičen odnos do raziskovanja in uporabe raziskovalnih spoznanj pri delu $\mathrm{v}$ razredu. Raziskovalci poskušajo svoje ugotovitve pojasniti s tem, da učitelji pogosto zaznavajo, da imajo ugotovitve raziskav omejeno praktično vrednost ter da zaznavajo prevelik razkorak med teorijo in prakso, saj menijo, da so raziskovalci, ki izvajajo raziskave, premalo v stiku z učitelji praktiki (Gore in Giltin, 2004).

Tako prihodnji učitelji kot tudi učitelji eksperti so izveden raziskovalni projekt ocenili kot koristen za razumevanje psiholoških razsežnosti pedagoškega dela $\mathrm{v}$ razredu. Izpostavili so, da se s pomočjo raziskovanja razvija občutljivost za psihološke probleme, s katerimi se učitelji srečujejo $\mathrm{v}$ razredu, ter možnost povezovanja teoretičnega in praktičnega znanja. Zanimiva je ugotovitev, da mentorji oz. eksperti statistično značilno višje ocenjujejo koristnost izvedenega raziskovalnega projekta v primerjavi s prihodnjimi učitelji (študenti), kar kaže na to, da ustrezno razumejo pomen raziskovanja $\mathrm{v}$ poučevalni praksi in njegovo vlogo pri razumevanju, podpori in izboljšavi poučevanja (Admiraal idr., 2016; Lamanauskas in Augiene, 2017). Razlike bi bilo mogoče pojasniti z domnevo, da imajo eksperti bistveno širši vpogled $\mathrm{v}$ področje poučevanja ter več strokovnega znanja v primerjavi s prihodnjimi učitelji. Prihodnji učitelji se glede na faze profesionalnega razvoja učiteljev denimo $\mathrm{v}$ Hubermanovem modelu (Huberman, 1989, 2002) nahajajo na začetku vstopa $\mathrm{v}$ kariero $\mathrm{v}$ fazi preživetja in odkrivanja, ko se ukvarjajo predvsem z vprašanji lastne kompetentnosti za poučevanje. Mentorji oz. eksperti pa se nahajajo na stopnji stabilizacije, za katero sta značilna prepričanost $\mathrm{v}$ lastna strokovna znanja in kompetence ter aktivno eksperimentiranje (preizkušanje različnih materialov, nalog, pristopov in uvajanje novosti ter sprememb v poučevalne prakse; glej tudi Hargreaves in Fullan, 2012), kar se najverjetneje izraža v odgovorih ekspertov na postavljena vprašanja.

Pri oblikovanju pozitivnih stališč prihodnjih učiteljev ter učiteljev praktikov do raziskav na področju izobraževanja je pomembno, da so ti o njih informirani in poznajo njihovo uporabno vrednost. Krek in Vogrinc (2008) ugotavljata, da izkušnje, ki jih imajo učitelji z raziskovalnim delom, pozitivno vplivajo na njihovo pripravljenost za prihodnje vključevanje $\mathrm{v}$ raziskovalno delo. Konkretne izkušnje vključevanja v raziskovanje torej pomembno doprinesejo $\mathrm{k}$ razvoju pozitivnih stališč do empirično podprtega poučevanja, kar pa pripomore k učiteljevemu strokovnemu razvoju ter nenazadnje h kakovostnemu poučevanju. Prihodnji učitelji bi morali biti zato že v fazi dodiplomskega izobraževanja deležni kakovostnega usposabljanja na področju raziskovanja ter pridobiti pozitivne izkušnje z raziskovalnim delom. Dodiplomski programi izobraževanja učiteljev naj bi spodbujali pripravljenost za raziskovanje tako, da prihodnje učitelje že ob začetku pedagoške kariere usposobijo za reflektiranje svojega dela. Prihodnji učitelji morajo med študijem pridobiti temeljna znanja o raziskovanju (metodologija, statistika), ki se smiselno povezujejo $\mathrm{z}$ vsebinskimi znanji (na primer kot v primeru te raziskave $\mathrm{z}$ vsebinami s področja pedagoške psihologije), tako da študenti spoznajo, kako lahko pridobljena temeljna znanja uporabijo ob konkretnih problemih, s katerimi se bodo srečevali v pedagoški praksi (Hennessy in Lynch, 2019; Krek in Vogrinc, 2008, Razdevšek-Pučko, 1990).

$\mathrm{V}$ prihodnje bi bilo nadvse zanimivo raziskati tudi, v kolikšni meri učitelji praktiki (eksperti) s pozitivnimi stališči do raziskovalnih spoznanj dejansko uporabljajo raziskovanje za izboljšanje kakovosti lastnega pedagoškega dela. Raziskovanje bi bilo smiselno tudi razširiti, in sicer z vključitvijo ravnateljev osnovnih šol. Izsledki novejše raziskave, ki sta jo opravila Brown in Zhang (2017) namreč kažejo, da predstavlja podpora vodstva pomemben dejavnik, ki vpliva na to, ali se bodo učitelji vključevali v raziskave na področju izobraževanja. Avtorja izpostavljata pomen vzpostavljanje šolske kulture, ki z ustreznim finančnim in strokovnim vrednotenjem raziskovalnega dela podpira in spodbuja učitelje, da se aktivno vključujejo v raziskovalno delo.

Dodiplomsko izobraževanje prihodnjih učiteljev ima ključno vlogo pri podpori razvoja učiteljeve pripravljenosti za raziskovanje. Konkretne izkušnje z vključevanjem v raziskovalno delo, ki jih študenti pridobijo v okviru študija ter konstruktivne in avtentične povratne informacije, lahko pozitivno doprinesejo $\mathrm{k}$ razvoju učitelja raziskovalca, ki raziskovanje uporablja za refleksijo in izboljšanje lastnega pedagoškega dela. Po besedah Razdevšek-Pučko (2013) sodobna družba znanja namreč zahteva od učiteljev prevzemanje nekaterih novih vlog, za katere mora biti učitelj odprt za spremembe, motiviran za vseživljenjsko učenje in stalni strokovni razvoj. Slednje pa nenazadnje terja premislek o selekcijskih postopkih, »ki bi že na začetku izbrali potencialne kandidate za tako zahtevne naloge« (str. 10) učiteljskega poklica, med katerimi zavzema osrednje mesto tudi ozaveščenost o uporabi empirično podprtih poučevalnih praks.

Uporabnost raziskovalnih ugotovitev je predvsem v ozaveščanju izobraževalcev prihodnjih učiteljev o pomenu kultiviranja pozitivnega odnosa učiteljev do empirično podprtega poučevanja. $\mathrm{Za}$ spodbujanje raziskovalne kulture pri prihodnjih učiteljih so namreč zelo pomembni visokošolski učitelji, ki morajo biti seznanjeni z najnovejšimi raziskovalnimi izsledki na njihovem strokovnem področju. Vrednost te raziskave predstavlja konkretna izvedba raziskovalnega projekta $\mathrm{v}$ šolskem kontekstu ter dopolnitev kvantitativnih ugotovitev $\mathrm{z}$ analizo odprtih odgovorov udeležencev. $\mathrm{V}$ raziskavi nismo nadzorovali vpliva izvedbe raziskovalnega projekta na stališča udeležencev, natančneje razlik v stališčih pred in po izvedbi raziskovalnega projekta nismo preverjali, saj v tako kratkem času ne gre pričakovati, da se bodo stališča pomembno spremenila (Borg, 2011; Urmson, 2003). Raziskavo bi bilo v prihodnje smiselno razširiti in vključiti tudi prihodnje učitelje Pedagoške fakultete Univerze v Mariboru ter Univerze na Primorskem, saj bi tako pridobili natančnejši vpogled v slovenski kontekst.

$Z$ vidika predstavljenih empiričnih rezultatov bi bila za premostitev opaženega razkoraka med teorijo in prakso 
potrebna vzpostavitev partnerskega odnosa med raziskovalci na področju izobraževanja ter učitelji praktiki. Dolžnost raziskovalcev je, da učiteljem ponudijo povratno informacijo ter jih vključijo v oblikovanje intervencij in eksperimentiranje $\mathrm{z}$ inovativnimi pedagoškimi pristopi. Učitelje $\mathrm{v}$ praksi je potrebno vseskozi spodbujati, da ostanejo $\mathrm{v}$ stiku $\mathrm{z}$ najnovejšimi trendi in raziskavami na področju izobraževanja preko programov strokovnega izpopolnjevanja ter udeležbe na različnih izobraževanjih (npr. delavnice, seminarji), kjer se razpravlja o rezultatih različnih raziskav in načrtuje njihovo učinkovito uporabo v praksi (glej tudi Ahuja, 2012).

\section{Literatura}

Admiraal, W., Buijs, M., Claessens, W., Honing, T. in Karkdijk, J. (2017). Linking theory and practice: Teacher research in history and geography classrooms. Educational Action Research, 25(2), 316-331.

Ahuja, S. (2012). Research results for quality schooling: Bridging the gap between research and practice. Journal of Educational Studies, Trends \& Practices, 2(2), 206-214.

Ajzen, I. in Fihbein, M. (1977). Attitude-behavior relations: A theoretical analysis and review of empirical research. Psychological Bulletin, 84(5), 888-918.

Akcoltekin, A., Engin, A. O. in Sevgin, H. (2017). Attitudes of high school teachers to educational research using classification-tree method. Eurasian Journal of Educational Research, 68, 19-47.

Albarracin, D., Johnson, B. T., Zanna, M. P. in Kumkale, G. T. (2005). Attitudes: Introduction and scope. V D. Albarracin, B. T. Johnson in M. P. Zanna (ur.), The handbook of attitudes (str. 3-19). Mahwah, NJ, ZDA: Lawrence Erlbaum Associates.

Berliner, D. (2001). Learning about and learning from expert teachers. International Journal of Educational Research, 35(5), 463-482.

Beycioglu, K., Ozer, N. in Ugurlu C. T. (2010). Teachers' views on educational research. Teaching and Teacher Education, 26, 1088-1093.

Borg, S. (2003). Teacher cognition in language teaching: A review of reseach on what language teachers think, know, believe, and do. Language Teaching, 36(2), 81-109.

Borg, S. (2011). The impact of in-service teacher education on language teachers' beliefs. System, 39(3), 370-380.

Brislin, R. W. (1986). The wording and translation of research instruments. V W. L. Lonner in J. W. Berry (ur.), Field methods in cross-cultural research (str. 137-164). Newbury Park, CA, ZDA: Sage.

Brow, C. in Zhang, D. (2017). Accounting for discrepancies in teachers' attitudes towards evidence use and actual instances of evidence use in schools. Cambridge Journal of Education, 47(2), 277-295.

Byman, R., Krokfors, L., Toom, A., Maaranen, K., Jyrhämä, R., Kynäslahti, H. in Kansanen, P. (2009). Educating inquiry-oriented teachers: Students' attitudes and experiences towards research-based teacher education. Educational Research and Evaluation, 15(1), 72-92.
Caena, F. (2011). Literature review: Teachers' core competences: Requirements and development European Commission. Directorate - General for Education and Culture. Pridobljeno s http://ec.europa.eu/dgs/education culture/repository/education/policy/strategic-framework/ doc/teacher-competences_en.pdf

Cain, T. (2015). Teachers' engagement with published research: Addressing the knowledge problem. The Curriculum Journal, 26(3), 488-509.

Cochran-Smith, M. (2005). Teacher educators as researchers: Multiple perspectives. Teaching and Teacher Education, 21, 219-225.

Craig, L. J. (2009). Teacher research and teachers as researcher. V L. J. Saha, in A. G. Dworkin (ur.), International handbook of research on teachers and teaching (str. 6170). New York, NY, ZDA: Springer.

Ekiz, D. (2006). Primary school teachers' attitudes towards educational research. Educational Sciences: Theory \& Practice, 6(2), 395-402.

Everton, T., Galton, M. in Pell, T. (2002). Educational research and the teacher. Research Papers in Education, 17(4), 373-401.

Gitlin, A., Barlow, L., Burbank, M. D., Kauchak, D. in Stevens, T. (1999). Pre-service teachers' thinking on research: Implications for inquiry oriented teacher education. Teaching \& Teacher Education, 15, 753-769.

Gore, J. M. in Gitlin, A. D. (2004). [Re]Visioning the academic teacher divide: Power and knowledge in the educational community. Teachers and Teaching: Theory and Practice, 10, 35-58.

Greenwood, C. R. in Abbott, M. (2001). The research to practice gap in special education. Teacher Education and Special Education, 24(4), 276-289.

Hargreaves, D. H. (1996). Teaching as research-based profession: Possibilities and prospects, The Teacher Training Agency Annual Lecture. London, Združeno kraljestvo: Teacher Training Agency.

Hargreaves, A. \& Fullan, M. (2012). Professional capital: Transforming teaching in every school. New York, NY, ZDA: Teachers College Press.

Hennessy, J. in Lynch, R. (2019). Straddling the marshy divide: Exploring pre-service teachers' attitudes towards teacher research. Educational Review, 71(5), 595-616.

Hiebert, J., Gallimore, R. in Stigler, J. W. (2002). A knowledge base for the teaching profession: What would it look like and how can we get one? Educational Researcher, 31, $3-15$.

Huberman, M. A. (1989). The professional life cycle of teachers. Teachers College Record, 91(1), 31-57.

Huberman, M. A. (2002). Moving towards the inevitable: The sharing of research in education. Teachers and Teaching, 8(3), 257-268.

IBM Corporation. (2016). IBM SPSS statistics for Macintosh, Version 23.0. Armonk, NY, ZDA: IBM Corporation.

İlhan, N., Şekerci A. R., Sözbilir, M. in Yıldırım, A. (2013). Eğitim araştırmalarına yönelik öğretmen tutum ölçeğinin geliştirilmesi: Geçerlik ve güvenirlik çalışması [The development of teachers attitude scale towards educational research: the validity and reliability study]. Western Anatolia Journal of Educations Sciences, 4(8), 31-56. 
İlhan, N. Yilmaz, Z. A. in Dede, H. (2015). Attitudes of preservice science teachers towards educational research and their science teaching efficacy beliefs in Turkey. Journal of Baltic Science Education, 14(2), 183-193.

Joram, E. (2007). Clashing epistemologies: Aspiring teachers' practicing teachers', and professors' beliefs about knowledge and research in education. Teaching and Teacher Education, 23, 123-135.

Juriševič, M. in Žerak, U. (2016). Vprašalnik o izvedenem študijskem raziskovalnem projektu. Neobjavljeno gradivo, Oddelek za temeljni pedagoški študij, Pedagoška fakulteta, Ljubljana.

Krek, J. in Vogrinc, J. (2008). Učitelj - raziskovalec vzgojnoizobraževalne prakse [Teacher-researcher of educational practice]. V J. Krek, T. Hodnik Čadež, J. Vogrinc, B. Sicherl Kafol, T. Devjak in V. Štemberger (ur.), Učitelj $v$ vlogi raziskovalca: Akcijsko raziskovanje na področjih medpredmetnega povezovanja in vzgojne zasnove v javni šoli [Teacher in a researcher role: Action research in cross-curricular integration and educational design in public school] (str. 23-57). Ljubljana, Slovenija: Pedagoška fakulteta.

Lamanauskas, V. in Augiene, D. (2017). Scientific research activity of students pre-service teachers of sciences at university: The aspects of understanding, situation and improvement. EURASIA Journal of Matematics Science and Technology Education, 13(1), 223-236.

Leat, D., Reid, A. in Lofthouse, R. (2015). Teachers' experiences of engagement with and in educational research: What can be learned from teachers' views. Oxford Review of Education, 41(2), 270-268.

Maio, G. R. in Haddock, G. (2007). Attitude change. V A. W. Kruglanski in T. Higgins (ur.), Social psychology: Handbook of basic principles (str. 565-586). New York, NY, ZDA: The Guilford Press.

Pajares, F. (1992). Teachers' beliefs and educational research: Cleaning up a messy construct. Review of Educational Research, 62(3), 307-332.

Pendry, A. in Husbands, C. (2000). Research and practice in history teacher education. Cambridge Journal of Education, 30, 321-334.

Razdevšek-Pučko, C. (1990). Vpliv učiteljevih vzgojnoizobraževalnih stališč na njegovo pedagoško delo ter možnost njihovega spreminjanja (neobjavljena doktorska disertacija) [Influence of teacher's educational attitudes on his pedagogical work and the possibility of changing them (unpublished doctoral dissertation)]. Filozofska fakulteta Univerze v Ljubljani, Slovenija.

Razdevšek-Pučko, C. (2013). Kakšnega učitelja potrebuje (pričakuje) današnja (in jutrišnja) šola? [What kind of teacher does today's (and tomorrow's) school need (expects)]. Didakta, 162(22), 8-10.

Rosseel, Y. (2012). lavaan: An R Package for Structural Equation Modeling. Journal of Statistical Software, 48(2), 1-36.

RStudio Team (2015). RStudio: Integrated development for R. Boston, MA, ZDA: RStudio.
Shaw, K., Holbrook, A., Scevak, J. in Bourke, S. (2008). The response of pre-service teachers to a compulsory research project. The Australian Educational Researcher, 31(3), 89-109.

Taylor, M. (2013). Social science teachers' utilisation of best evidence syntheis research. New Zealand Journal of Educational Studies, 48(2), 34-50.

Tosun, C. (2014). Pre-service teachers' opinions about the course on scientific research methods and the levels of knowledge and skills they gained in this course. Australian Journal of Teacher Education, 39(10), 96-112.

Ule, M. (2009). Socialna psihologija: Analitični pristop $k$ življenju v družbi [Social psychology: An analytical approach to life in society]. Ljubljana, Slovenija: Fakulteta za družbene vede Univerze v Ljubljani.

Urmson, A. (2003). Learning to teach English in Honk Kong: The opinions of teachers in training. Language and Educatuion, 17(2), 112-137.

Vogrinc, J. (2008). Kvalitativno raziskovanje na pedagoškem področju [Qualitative research in the pedagogical field]. Ljubljana, Slovenija: Pedagoška fakulteta Univerze v Ljubljani.

Walter, O. in Hen, M. (2012). Bridging the gap between research and practice in teachers preparation. Journal of Ecuation and General Studies, 1(7), 216-224. 